\title{
Can Greater Flamingo Recognize Fertile vs. Infertile Egg? A Single Case Study
}

\author{
Camillo Sandri' ${ }^{1}$, Barbara Regaiolli2 ${ }^{*}$, Matilde Franchin ${ }^{3}$, Alessandra Piccirillo ${ }^{3}$, Caterina Spiezio ${ }^{2}$ \\ ${ }^{1}$ Veterinary Department, Parco Natura Viva-Garda Zoological Park, Bussolengo, Italy \\ ${ }^{2}$ Research \& Conservation Department, Parco Natura Viva-Garda Zoological Park, Bussolengo, Italy \\ ${ }^{3}$ Department of Comparative Biomedicine and Food Science (BCA), University of Padua, Padua, Italy \\ Email: camillo.sandri@parconaturaviva.it, *barbara.regaiolli@parconaturaviva.it, matilde.franchin@gmail.com, \\ alessandra.piccirillo@unipd.it, spiezio@parconaturaviva.it
}

How to cite this paper: Sandri, C., Regaiolli, B., Franchin, M., Piccirillo, A. and Spiezio, C. (2017) Can Greater Flamingo Recognize Fertile vs. Infertile Egg? A Single Case Study. Open Journal of Animal Sciences, 7, 232-239.

https://doi.org/10.4236/ojas.2017.72018

Received: March 29, 2017

Accepted: April 27, 2017

Published: April 30, 2017

Copyright (C) 2017 by authors and Scientific Research Publishing Inc. This work is licensed under the Creative Commons Attribution International License (CC BY 4.0).

http://creativecommons.org/licenses/by/4.0/

\begin{abstract}
Fertility of captive flamingos varies between flocks, species and seasons. Individuating infertile eggs could be helpful to facilitate important decisions. Wild animals could be encouraged to abandon the nest or not, whereas in captivity removing non-viable egg would lead birds to lay a new one. The aim of this study was to investigate the parental behaviour of a pair of greater flamingos (Phoenicopterus roseus) in the presence of a fertile and an infertile egg. Data on the posture and behaviours of the pair on the nest were collected over two different periods: first period-an infertile egg was laid; second period-a fertile egg was laid. For each period, 28 ten-minute sessions per flamingo partner were run. Results revealed that female flamingo spent significantly more time standing on the nest in the first than in the second period $(P=0.010)$. Moreover, when standing on the nest, the female performed significantly more egg-care behaviour (attention to the egg, egg rotation/moving) in the first than in the second period $(P=0.010)$. No significant differences between periods emerged in the male flamingo posture on the nest and behaviours. Findings from this study suggest that female flamingos stand on the nest longer if the egg is infertile, paying more attention and examining it deeply. This study provides new insights into greater flamingo parent-embryo communication. Future research is needed to improve our knowledge on this topic, as well as on the husbandry of this species in the controlled environment.
\end{abstract}

\section{Keywords}

Phoenicopterus roseus, Egg Fertility, Egg Care, Parental Behaviour

\section{Introduction}

Flamingos are colonial birds and the optimal flock size is at least 20 individuals 
in zoos. However, successful breeding occurs with flocks of more than 40 birds. Fertility of captive flamingos varies between flocks, species and seasons. Egg production and incubation require a great time and energy investment in birds. Individuating infertile eggs could therefore be helpful when decisions on whether or not to abandon the nest are needed [1]. Similarly, in captivity, the knowledge of egg fertility is useful to make informed decisions on the incubation process. For example, removing infertile or dummy eggs from the nest would encourage birds to lay further eggs, increasing their likelihood to breed successfully. In flamingos, pairs that laid an infertile first egg will often produce fertile second eggs [2]. Bird species, such as ostriches, are able to recognize infertile eggs and remove them from the clutch [3]. In addition, previous research suggested that odour cues of the egg provide information on the embryo development and may also be informative of the health status. Thus, egg odour might also be involved in fertility determination, mediating parental behaviour [1]. Moreover, egg odours have been found to solicit the behaviour of the incubating bird, improving the quality of parental care [1] [4]. However, the literature on parent and developing embryo communication in birds is lacking and studies are needed [1].

The aim of this study was to investigate the parental behaviour of a pair of greater flamingos (Phoenicopterus roseus) in the presence of a fertile and an infertile egg.

The current study was carried out as part of a project on parental care behaviour of captive greater flamingos, focusing on postures and behaviours of males and females during the incubation period. One of the study pairs of greater flamingos was observed incubating an egg that was subsequently found to be infertile. After the removal of the non-viable egg, the pair laid a second one. Thus, a further period of data collection was carried out, in order to investigate whether and how egg fertility might affect flamingo parental behaviour.

\section{Materials \& Methods}

\subsection{Study Subjects and Area}

The study was carried out with a pair of greater flamingo hosted in a flock of 110 individuals of different age, 53 females and 57 males, housed at Parco Natura Viva-Garda Zoological Park in Italy. Data were collected during 2014 greater flamingo breeding season. The enclosure had an area of $1100 \mathrm{~m}^{2}$ and was mainly made of a water pond with two islands, used by the flamingos to build their nest mounds and rear the chicks. The basal structure of the nest mound was built by humans, whereas flamingo pairs completed the nest construction.

The greater flamingo diet was made of a specific pellet composed of cereals, vegetables, oils and fats, algae, shellfish, vitamins and mineral salts.

Flamingos were identified through a ring on one leg. The ring differed in colour and letters (three-letter combination). The study pair, the female PCF (red) and the male KUA (white), were monogamous since 2008 and both flamingos were over 20 years old. 


\subsection{Data Collection and Analysis}

The observation of the greater flamingo pair was carried out in 2014, during the peak of the breeding activity, specifically at the time of egg incubation. The pair was observed during two different periods: in the first period, the egg incubated by the pair was infertile, whereas the egg laid in the second period was fertile. The infertile egg was laid on March, $6^{\text {th }}$ and removed from the nest on April, $4^{\text {th }}$ (after the usual flamingo incubation period expired), to encourage the pair to lay a new egg [2]. The second egg was laid on April, $17^{\text {th }}$ and hatched successfully on May, $15^{\text {th }}$.

Within each period, 28 ten-minute sessions for each flamingo partner were run over a 14 day period. In particular, two sessions per day were carried out, one in the morning and one in the afternoon. Data collection sessions were run randomly and evenly during the periods. A continuous focal animal sampling method was used to collect data on the parental care behaviour of both flamingo partners, specifically when they were on the nest. In particular, data on the posture of the bird and the behavioural category performed were recorded. Regarding the posture, each flamingo could be sitting or standing. The behavioural categories collected in the study were agonistic behaviour, such as extending the neck and peak at other birds [5] [6], incubation, nest-building, self-directed comfort behaviour (preening, stretching and scratching) and egg-care related behaviours. Particular attention was given to the egg-care related behaviours, that included attention to the egg and rotating/moving the egg [7] [8] [9] [10].

A single-case analysis was performed to compare data of each flamingo partner between the two periods [11] [12] and non-parametric statistic tests were used [13]. In particular, the Wilcoxon test was carried out to compare the duration of different postures and behaviours performed on the nest of the male and the female between the two periods. Significance level was set at $P<0.05$. The values in brackets in the result section are mean duration \pm SD in seconds.

\section{Results}

Flamingo parents could stay either on the nest (sitting or standing) or out of the nest. In the first period, the female flamingo spent $61 \%$ of the total observation time sitting on the nest, $10 \%$ standing on the nest and $29 \%$ out of the nest (Figure 1). The male flamingo spent $72 \%$ of the total observation time out of the nest, $27 \%$ sitting on the nest and $1 \%$ standing on the nest (Figure 2).

In the second period, the female flamingo spent $63 \%$ of the total observation time sitting on the nest, $1 \%$ standing on the nest and $36 \%$ out of the nest (Figure 1 ). The male flamingo spent $64 \%$ of the total observation time out of the nest, $33 \%$ sitting on the nest and 3\% standing on the nest (Figure 2).

\section{Postures on the nest}

Wilcoxon test revealed no significant difference in the time spent on the nest (regardless of standing or sitting) between the first (female: $857.36 \pm 453.12$; male: $342.64 \pm 453.12$ ) and the second period (female: $771.43 \pm 435.76$; male: $428.57 \pm 435.76)(Z=-0.690, P=0.490$, both sexes $)$. 


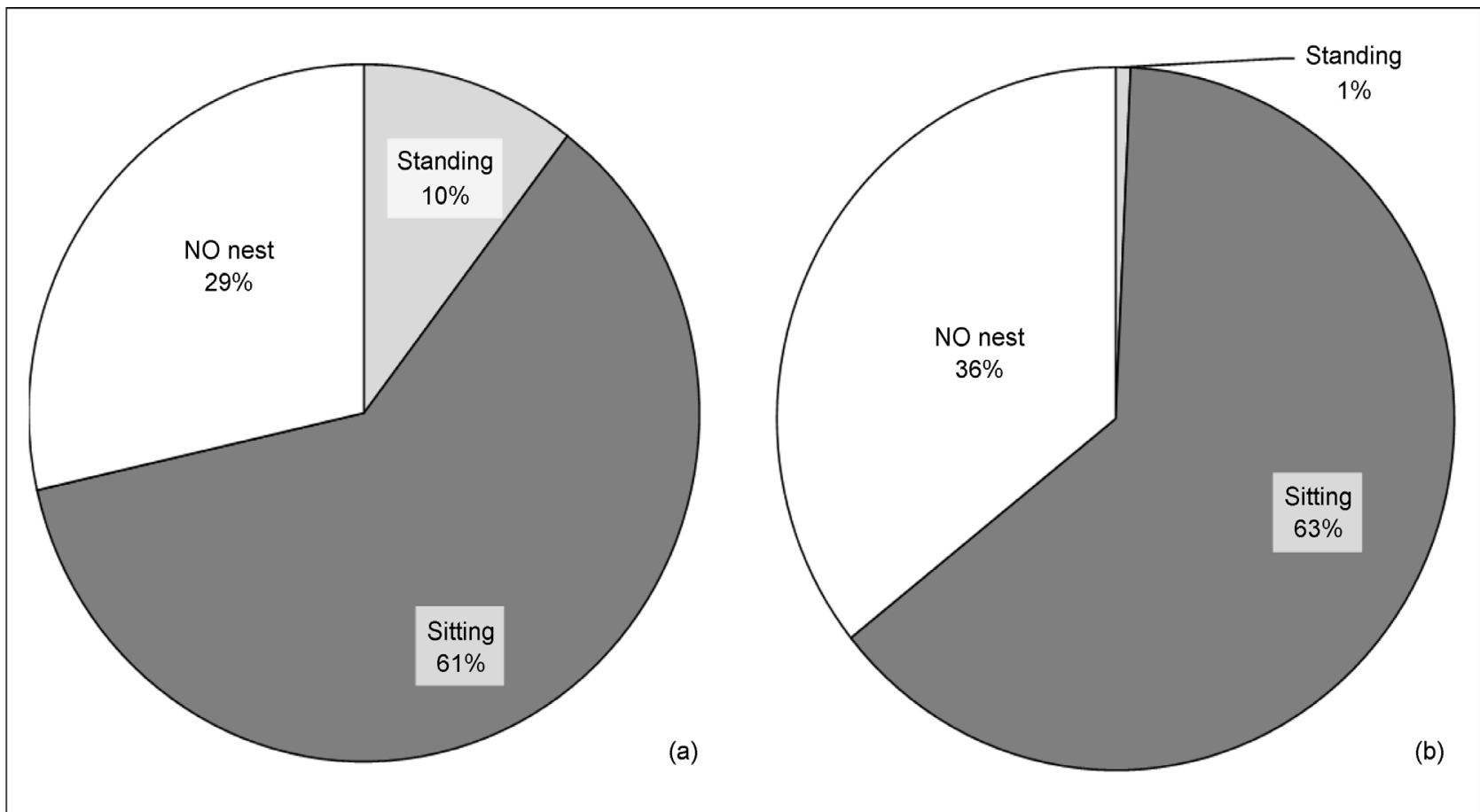

Figure 1. posture on the nest of the female flamingo in the first (a) and second (b) period. The pie chart reports the mean duration in seconds (\% on the total observation time) of time spent in different postures: standing on the nest, sitting on the nest or out of the nest (no nest).
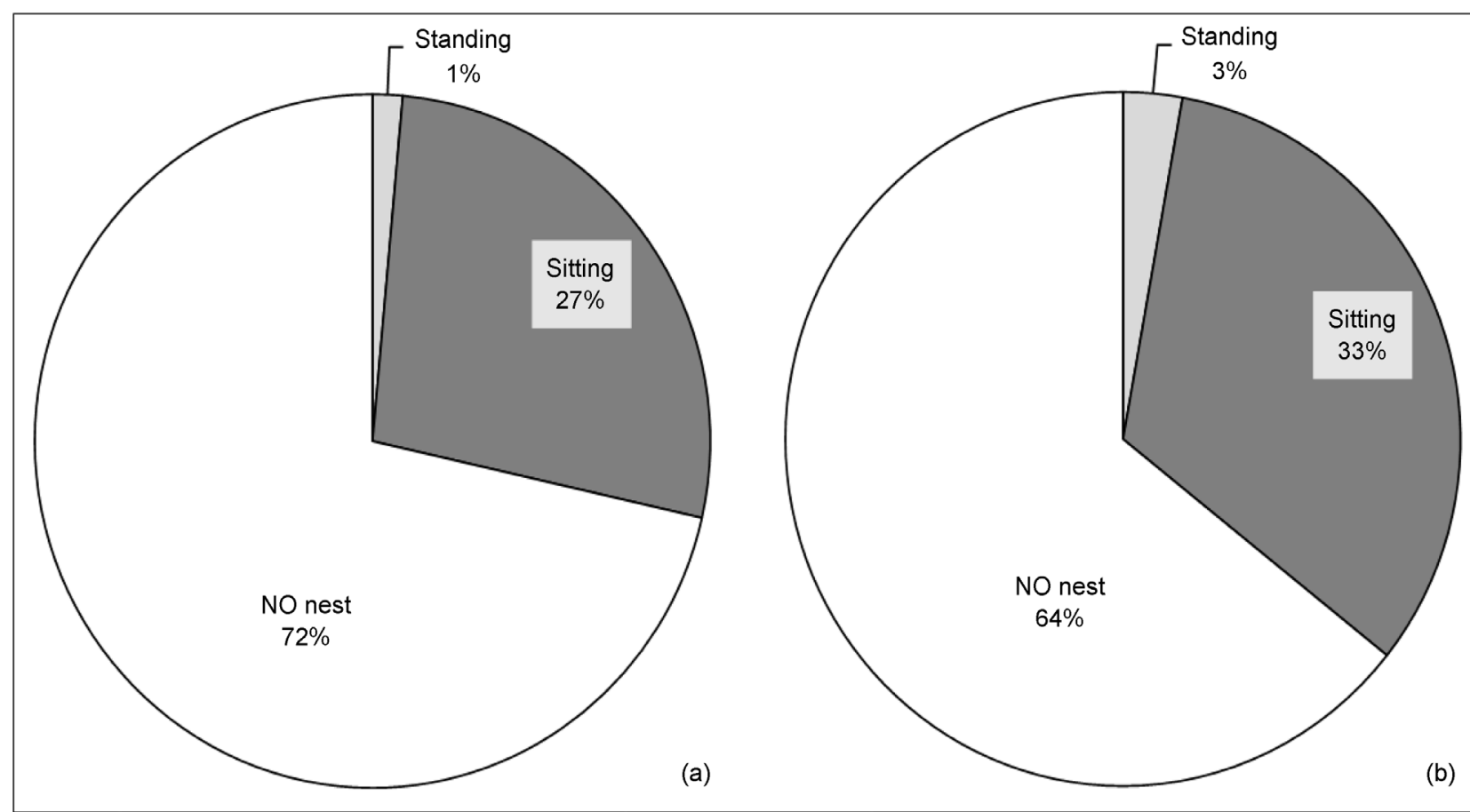

Figure 2. Posture on the nest of the male flamingo in the first (a) and second (b) period. The pie chart reports the mean duration in seconds (\% on the total observation time) of time spent in different postures: standing on the nest, sitting on the nest or out of the nest (no nest).

While on the nest, female and male flamingos could be standing or sitting. The Wilcoxon test revealed that the female spent more time standing in the first 
period $(124.5 \pm 148.18)$ than in the second period $(8.50 \pm 29.05)(Z=-2.578, P=$ $0.010)$, whereas no differences emerged for sitting between the first (732.86 \pm $401.55)$ and the second period $(762.93 \pm 427.65)(Z=-0.559, P=0.576)$ (Figure $1)$. For the male, no significant differences emerged for both standing (first period: $17.14 \pm 38.23$; second period: $33.93 \pm 93.98)(Z=-0.105, P=0.917)$ and sitting (first period: $325.50 \pm 424.25$; second period: $394.64 \pm 387.31)(Z=-0.654$, $P=0.513)$.

\section{Behaviours performed standing on the nest}

When standing on the nest, the female performed significantly more agonistic behaviour, self-comfort behaviour and egg-care in the first than in the second period (Table 1, Figure 1). No significant differences were reported for any behavioural category performed by the male (Table 2).

When considering each egg-care related behaviour separately, the female performed significantly more attention to the egg $(Z=-2.490, P=0.013)$ and egg rotation/moving $(Z=-2.095, P=0.036)$ in the first than in the second period (Table 1). On the other hand, the Wilcoxon test revealed no significant differences between the two periods for the male in both attention to the egg and egg-rotation/moving $(P>0.05$, Table 2$)$.

\section{Behaviours Performed Sitting on the Nest}

When flamingo partners were sitting on the nest, no significant differences in any behavioural category (agonistic behaviour, incubation, nest-building and self-comfort behaviour) between the two periods were found for both the female (Table 1, Figure 1) and the male (Table 2) $(P>0.05)$.

Table 1. Behavioural categories performed by the female flamingo in the two study periods. For each behavioural category performed when standing and sitting on the nest, the table reports the mean duration \pm SD in seconds in each period (first and second). In addition, the Wilcoxon $Z$ and $P$ values for the comparison between the two periods are reported.

\begin{tabular}{|c|c|c|c|c|}
\hline \multicolumn{5}{|c|}{ Standing on the nest } \\
\hline & First period & Second period & $Z$ & $P$ \\
\hline Agonistic behaviour ${ }^{*}$ & $14.64 \pm 18.05$ & 0 & -2.668 & $0.008^{*}$ \\
\hline Self-comfort behaviour ${ }^{*}$ & $34.21 \pm 63.46$ & $2.50 \pm 8.27$ & -2.100 & $0.036^{\star}$ \\
\hline Egg-care ${ }^{\star}$ & $69.86 \pm 70.96$ & $6.00 \pm 20.78$ & -2.580 & $0.010^{*}$ \\
\hline Nest-building & $5.79 \pm 16.07$ & 0 & -1.342 & 0.180 \\
\hline \multicolumn{5}{|l|}{ Egg-care } \\
\hline Attention to the egg* & $63.50 \pm 67.88$ & $5.43 \pm 18.65$ & -2.49 & $0.013^{*}$ \\
\hline Egg-rotation/moving ${ }^{\star}$ & $6.36 \pm 7.80$ & $0.57 \pm 2.14$ & -2.095 & $0.036^{*}$ \\
\hline \multicolumn{5}{|c|}{ Sitting on the nest } \\
\hline Agonistic behaviour & $136.29 \pm 118.29$ & $122.14 \pm 116.91$ & -0.314 & 0.753 \\
\hline Incubation & $398.86 \pm 285.90$ & $414.07 \pm 297.08$ & -0.408 & 0.683 \\
\hline Nest-building & $166.00 \pm 214.65$ & $120.43 \pm 180.23$ & -0.157 & 0.875 \\
\hline Self-comfort behaviour & $31.71 \pm 50.78$ & $106.29 \pm 200.97$ & -0.549 & 0.583 \\
\hline
\end{tabular}

*Significant difference between the first and second period $(P<0.05)$. 
Table 2. Behavioural categories performed by the male flamingo in the two periods. For each behavioural category performed when standing and sitting on the nest, the table reports the mean duration \pm SD in seconds in each period (first and second). In addition, the Wilcoxon $Z$ and $P$ values for the comparison between the two periods are reported.

\begin{tabular}{|c|c|c|c|c|}
\hline \multicolumn{5}{|c|}{ Standing on the nest } \\
\hline & First period & Second period & $Z$ & $P$ \\
\hline Agonistic behaviour & $0.79 \pm 2.01$ & $0.14 \pm 0.53$ & -1.069 & 0.285 \\
\hline Self-comfort behaviour & $1.07 \pm 3.05$ & $19.29 \pm 70.73$ & -0.535 & 0.593 \\
\hline Egg-care & $15.29 \pm 33.68$ & $14.50 \pm 26.67$ & -0.105 & 0.917 \\
\hline Nest-building & 0 & 0 & $\#$ & $\#$ \\
\hline \multicolumn{5}{|l|}{ Egg-care } \\
\hline Attention to the egg & $13.29 \pm 30.03$ & $14.50 \pm 26.67$ & -0.105 & 0.917 \\
\hline Egg-rotation/moving & $2.00 \pm 4.62$ & 0 & -1.604 & 0.109 \\
\hline \multicolumn{5}{|c|}{ Sitting on the nest } \\
\hline Agonistic behaviour & $54.64 \pm 73.10$ & $86.86 \pm 98.33$ & -1.275 & 0.202 \\
\hline Incubation & $183.71 \pm 253.06$ & $206.93 \pm 222.86$ & -0.204 & 0.838 \\
\hline Nest-building & $75.21 \pm 148.88$ & $36.43 \pm 102.82$ & -0.734 & 0.463 \\
\hline Self-comfort behaviour & $11.93 \pm 27.59$ & $64.43 \pm 187.67$ & -0.889 & 0.374 \\
\hline
\end{tabular}

${ }^{*}$ Significant difference between the first and second period $(P<0.05)$.

\section{Discussion and Conclusion}

The literature on parent and developing embryo communication in birds is still lacking [1]. This study aimed at investigating the presence of differences in the parental behaviour of a pair of greater flamingo in the presence of an infertile and a fertile egg. First, species-specific parental behaviours, such as egg-care, comfort behaviour, nest-building and protection [2] [7] [8] [9] [10] were found in the first and in the second period in both the female and male flamingos, suggesting an overall good welfare and wilderness of the subjects [14]. Second, the behaviour of the female flamingo varied significantly between the two periods and this variability might occur based on egg fertility.

This study focused both on the posture of the flamingos on the nest and the behaviours that were performed. Regarding the flamingo partner posture, both the female and male partner spent approximately the same amount of time on the nest in the first and in the second period. However, the female spent significantly more time standing on the nest (not incubating the egg) in the first period, when the egg was infertile, than in the second period. No significant differences emerged for the male. When standing on the nest, study flamingos performed agonistic behaviours toward conspecifics, self-comfort behaviour and, importantly, egg-care related behaviours. All these behaviours were performed significantly more by the female in the first than in the second period, suggesting an effect of egg fertility on female flamingo behaviour. Particularly concerning egg-care related behaviour, the female paid more attention and looked at the egg for a significantly longer time when it was non-viable. Similarly, the female interacted significantly more with the infertile egg of the first period, rotating or 
moving it to a greater extent than in the second period. No significant differences emerged between the two periods for the male flamingo, suggesting that egg fertility seems to affect only the behaviour of the female. On the other hand, when both female and male flamingos were sitting on the nest, no significant differences were observed between the two periods in any of the behaviours performed.

Results from this study underline that the presence of a non-viable egg led female flamingo to stand on the nest for a longer time, presumably to better examine and give more attention to the egg. To our knowledge, this is the first study aimed at investigating the effect of egg fertility on the greater flamingo parental behaviour. Future research involving a larger sample of flamingo pairs is needed to better understand the interaction between flamingos and their egg/embryo. This kind of knowledge would provide new insights into the ecological role of parent-embryo communication and would improve the husbandry and breeding of greater flamingos in captivity.

\section{Acknowledgements}

The study was carried out using non-invasive techniques, through the observation of the live birds. The research procedure was in accordance with the EU Directive 2010/63/EU for animal research. We would like to thank Dr. Cesare Avesani Zaborra for allowing this study to take place in Parco Natura Viva. Furthermore, special thanks should be given to Giuseppe Alampi, and Carolina Sammarini, Parco Natura Viva zoo-keepers, for their hard work and for their precious help with the flamingo census and monitoring.

\section{References}

[1] Webster, B., Hayes, W. and Pike, T.W. (2015) Avian Egg Odour Encodes Information on Embryo Sex, Fertility and Development. PLOS ONE, 10, e0116345. https://doi.org/10.1371/journal.pone.0116345

[2] Pickering, S., Creighton, E. and Stevens-Wood, B. (1992) Flock Size and Breeding Success in Flamingos. Zoo Biology, 11, 229-234.

https://doi.org/10.1002/zoo.1430110402

[3] Shanawany, M.M. and Dingle, J. (1999) Ostrich Production System, Part 1-2. Food \& Agriculture Organization, Rome.

[4] Moreno, J. and Osorno, J.L. (2003) Avian Egg Colour and Sexual Selection: Does Eggshell Pigmentation Reflect Female Condition and Genetic Quality? Ecology Letters, 6, 803-806. https://doi.org/10.1046/j.1461-0248.2003.00505.x

[5] Stevens, E.F., Beaumont, J.H., Cusson, E.W. and Fowler, J. (1992) Nesting Behavior in a Flock of Chilean Flamingos. Zoo Biology, 11, 209-214. https://doi.org/10.1002/zoo.1430110309

[6] Farrell, M.A., Barry, E. and Marples, N. (2000) Breeding Behavior in a Flock of Chilean Flamingos (Phoenicopterus chilensis) at Dublin Zoo. Zoo Biology, 19, 227-237. https://doi.org/10.1002/1098-2361(2000)19:4<227::AID-ZOO1>3.0.CO;2-H

[7] Studer-Tiersch, A. (1975) Basle Zoo. In: Johnson, A. and Cezilly, F., Eds., The Greater Flamingo, T \& A D Poyser, Berkamsted, UK, 121-130.

[8] Brown, C. and King, C. (2005) Flamingo Husbandry Guidelines; A Joint Effort of 
the AZA and EAZA in Cooperation with WWT. Dallas Zoo, Dallas, TX.

[9] Beletsky, L. (2006) Birds of the World. The John Hopkins University Press, Baltimore, MD.

[10] Elphick, J. (2014) The World of Birds. Firefly Books, Buffalo, NY, London, United Kingdom and Ontario, Toronto.

[11] Barlow, D.H. and Hersen, M. (1984) Single-Case Experimental Designs: Strategies for Studying Behavior Change. 2nd Edition, Pergamon Press, New York.

[12] Jones, W.P. (2003) Single-Case Time Series with Bayesian Analysis: A Practitioner's Guide. Measurement and Evaluation in Counseling \& Development, 36, 28-39.

[13] Box, G., Jenkins, G.M. and Reinsel, G. (1994) Time Series Analysis: Forecasting and Control. 3rd Edition, Prentice Hall, Englewood Cliffs.

[14] Hosey, G., Melfi, V. and Pankhurst, S. (2013) Zoo Animals: Behaviour, Management, and Welfare-Second Edition. Oxford University Press, Oxford.

Submit or recommend next manuscript to SCIRP and we will provide best service for you:

Accepting pre-submission inquiries through Email, Facebook, LinkedIn, Twitter, etc. A wide selection of journals (inclusive of 9 subjects, more than 200 journals)

Providing 24-hour high-quality service

User-friendly online submission system

Fair and swift peer-review system

Efficient typesetting and proofreading procedure

Display of the result of downloads and visits, as well as the number of cited articles

Maximum dissemination of your research work

Submit your manuscript at: http://papersubmission.scirp.org/

Or contact ojas@scirp.org 